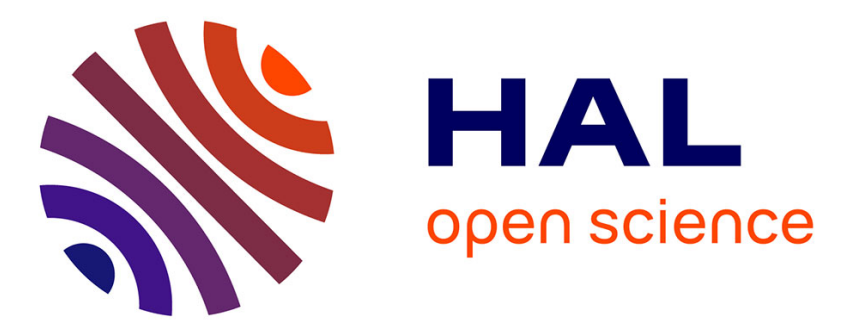

\title{
How does the expressiveness of leaders affect followership in domestic horses (Equus ferus caballus)?
}

Caroline Gérard, Mathilde Valenchon, Nicolas Poulin, Odile Petit

\section{To cite this version:}

Caroline Gérard, Mathilde Valenchon, Nicolas Poulin, Odile Petit. How does the expressiveness of leaders affect followership in domestic horses (Equus ferus caballus)?. Animal Cognition, 2020, 10.1007/s10071-020-01361-8 . hal-02492745

\section{HAL Id: hal-02492745 \\ https://hal.science/hal-02492745}

Submitted on 25 Nov 2020

HAL is a multi-disciplinary open access archive for the deposit and dissemination of scientific research documents, whether they are published or not. The documents may come from teaching and research institutions in France or abroad, or from public or private research centers.
L'archive ouverte pluridisciplinaire HAL, est destinée au dépôt et à la diffusion de documents scientifiques de niveau recherche, publiés ou non, émanant des établissements d'enseignement et de recherche français ou étrangers, des laboratoires publics ou privés. 
1

4

\section{How does the expressiveness of leaders affect followership in domestic horses (Equus} ferus caballus)?

(5

Gérard Caroline $\mathrm{e}^{\mathrm{a}_{1}}$, Valenchon Mathilde $\mathrm{a}^{\mathrm{a}^{*}}$, Poulin Nicolas $^{\mathrm{b}}$ \& Petit Odile ${ }^{\mathrm{a}}$

${ }^{\text {a }}$ Cognitive and Social Ethology group, CNRS, UMR 7247 Physiologie de la reproduction et des Comportements, F-37380 Nouzilly.

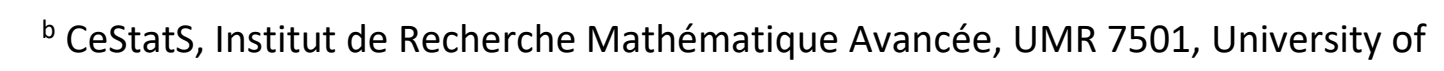
Strasbourg-CNRS, F-67000 Strasbourg

* C. Gérard \& M. Valenchon are co-first authors

Corresponding author: odile.petit@cnrs.fr 0388107457

Cognitive and Social Ethology group, UMR 7247, CNRS, 23 rue du Loess, BP 20, 67037 Strasbourg Cedex 02, France

${ }^{1}$ C. Gérard is now at UMR 7206 Eco-anthropologie, MNHN -Musée de l'Homme, 17 place du Trocadéro - 75116 Paris

${ }^{2}$ M. Valenchon is now at School of Veterinary Sciences, University of Bristol, Langford House, Langford, Bristol, BS40 5DU, U.K.

ORCID: Odile Petit 0000-0002-4340-7199 Gérard Caroline 0000-0002-6745-8257 Poulin

Nicolas 0000-0003-2740-7559 Valenchon Mathilde 0000-0003-0226-8433

\section{Abstract}

In collective movements, some individuals are more effective and attractive leaders than others. Parameters such as social network, personality and physiologic needs failed to explain why group members follow one leader more than another. In this study in the domestic horse, we propose to focus on the leader's attitude and its impact to the followers' recruitment during two conditions: spontaneous group departures or experimentally induced departures. We postulate that the expressiveness of the leader could enhance its attractiveness and thus produce a successful followership.

We found that a high expressiveness level is associated with a high curiosity score and with a low social status. This propensity to initiate while being expressive was higher in the experimental condition than in the spontaneous condition which was expected since the experimental procedure sought to increase the motivation of initiators with a highly appetent reward. Moreover, the more intense the leader's expressiveness is, the faster followers will 
join the movement regardless of the condition. This positive and dynamic attitude can be perceived as an attractive feature by the followers. Finally, we evidenced collective arousal in followers initiated by the leader that could be essential for group cohesion. The present study is the first to investigate the expressiveness level in animals, and provides new insights into the emergence of leadership.

Keywords: collective movement, consensus decisions, social status, personality, leadership, contagion mood

\section{Acknowledgments}

We warmly thank Thierry Bourgeois, Nans Burgarella, Rose Delacroix, Océane Liehrmann, Luc Martin, Virginie Nierat, Edouard Paumier, Louise Prévost, Julie Renard, Pierre Uhlrich, Lucile Villot for help with the experimental task. A USIAS grant awarded to O.P. funded the overall project.

\section{Introduction}

The coordination and synchronization of individuals to maintain cohesion in social species requires collective decisions (Conradt and Roper, 2003). Whatever the activity of the group, cohesion in social species is the only way to maintain the benefits of collective life, like reducing predation risk or increasing foraging success. Collective movements are an ideal context to investigate such collective decision-making, as group members have to agree about departure time and the direction in which they will move. The choice between different alternatives can be consistently made by one specific individual across events, such as the dominant male in gorillas (Gorilla gorilla beringei) (Watts, 2000) or the oldest female in African elephants (Loxodonta africana) (McComb et al., 2001). However, the decision can also be more consensual and involve a quorum or the whole group (Conradt and Roper, 2005). In this case, the decision is shared and the leadership is distributed between group members over contexts. This process may be the best means to manage any potential conflict of interest. Indeed, individuals from a given group differ in their age, sex, internal state and needs in many social species (Petit and Bon, 2010). Therefore, although a shared decision cannot be totally optimal for all group members, it reflects an average of all individual preferences - via a quorum or the whole group - and may provide the best compromise by keeping the consensus cost low for each individual (Conradt and Roper, 2003).

During a consensual decision process, some individuals can have a stronger influence than others and are considered as leaders. This leadership is distributed among group members in 
many species (Petit and Bon, 2010). For instance in groups of horses, every group member can initiate a collective movement (Bourjade et al., 2015; Briard et al., 2015, 2017), but some initiators appear to be more successful insofar that they are followed more quickly or display fewer failed initiations (in which no individuals follow the initiator). What makes a leader successfully trigger a collective movement? The location of individuals within the group when the movement starts is important. In groups of domestic geese (Anser domesticus) and cattle (Bos Taurus), individuals with a higher number of neighbors in close proximity are the most followed (Ramseyer et al., 2009a, 2009b). However, location does not seem to be correlated to leadership success in horses (Krueger et al., 2014). In horses, variations in group activity, orientation and dispersion before departure play a key role in collective decision processes but are not correlated to leader success (Bourjade et al., 2009; Briard, 2015). Dominance status has been shown to be a critical factor in leader success, with high-ranking individuals producing a faster joining process in several species including horses (Berger, 1977; Feist and McCullough, 1976) and rhesus macaques (Macaca mulatta), (Sueur and Petit, 2008a). However, more recent studies in horses did not confirm these results, showing a lack of correlation between dominance hierarchy and initiation success (Bourjade et al., 2015; Briard et al., 2015). The affiliative social network has been linked with inter-individual differences in initiation success in Tonkean macaques (Macaca tonkeana) (Sueur et al., 2009) and brown lemurs (Eulemur fulvus fulvus) (Jacobs et al., 2011). However, social centrality is not correlated with initiation propensity in horses (Krueger et al., 2014). But inter-individual affinities do however explain the dynamic of the joining phase in terms of spatial organization, but not in terms of duration (Briard et al., 2015). Amongst individual factors, age and sex are important factors for the initiation of movements in several species. For instance, adult females initiate a majority of movements in European bison (Bison bonasus) (Ramos et al., 2015), while male chacma baboons (Papio ursinus) initiate group movements more often than females (Sueur, 2011). Age or sex do not influence the initiation propensity or the joining latency in horses (Bourjade et al., 2015; Briard et al., 2017; Krueger et al., 2014). However, as observed in baboons in high-risk contexts such as crop-raiding (Schweitzer et al., 2017), personality has a strong influence with bold individuals initiating movements more frequently, in horses (Briard et al., 2015). Yet, these individuals are not more successful than others in the group. The relationship between energetic needs and leadership has also been explored, based on the hypothesis that an individual with higher energetic needs has a strong interest to initiate 
foraging movements more often and more successfully. This hypothesis has been confirmed in the plains zebra (Equus burchellii), where females are more likely to initiate movement when they are lactating (Fischhoff et al., 2007). However, no consistent relationship has been found between energetic needs and leadership in horses (Corbin et al., 2019).

At this point, we still need to pinpoint what makes an initiator more efficient than another in being followed by the group, thus making it a successful leader. In this study in the domestic horse, we propose to focus on the leader's attitude and its impact to the followers' recruitment. In several species, individuals that express signals such as glances, pauses or vocalizations are followed by more individuals than other initiators (Meunier et al., 2008; Sueur and Petit, 2008b). These signals can be voluntarily emitted by leaders and are supplemented by clues that the followers perceive in the behavior and/or posture of the leader. Despite their potential importance in the decision-making process of followers, these signals or clues have never been studied in horses. Inter-individual differences in the quantity or quality of signals or clues emitted by the leader could explain the different success rates observed in this species. This underlines the importance of determining which signals or clues are used by horses during an initiation. Furthermore, a combination of behaviors could enhance the accuracy of the message, regardless of whether it is sent to followers voluntarily or not (see " the backup signal hypothesis " (Johnstone, 1996)). By recording these signals or clues, we expect to establish individual profiles and evaluate their stability over time and across contexts. Moreover, we will verify if some signals/profiles are linked to the personality of initiators. In a second step, we will test if a more expressive individual will be more followed than another initiator. The third step of this study is to analyze how social status of the leader influences the followership in terms of hierarchy and centrality. We hypothesize that a leader's expressiveness could differ according to its social status. However, we cannot predict the direction of that relationship. Indeed, both dominants and subordinates could be more expressive for opposite reasons, i.e. respectively, because of an over-confidence conferred by a greater social influence on others, or because of a need to compensate a weaker social position. Finally, we use the hypothesis of contagion mood (De Marco et al., 2011) to examine the followership process. From the leader to the last follower, the level of expressiveness displayed by one individual could be transmitted to the next in the collective movement. This could explain the progressive and continuous joining process and could thus contribute to maintaining group cohesiveness. 
These hypotheses are tested by observing the collective movements of three stable groups of six females. The group departures are spontaneous or triggered by an experimental manipulation and continuously observed. The spontaneous context reflects collective movements that occur naturally while the experimentation simplifies the context and prevents any movement preparation. In the spontaneous condition, every group movement initiated by any group member is recorded. In the experimental condition, the group of horses is enclosed in a pen and one horse is removed from the group and shown where a food source is located. Next, the informed horse is returned to the pen and, then, the enclosure is opened. With such a procedure, we decide upon the time of departure, the trajectory and the identity of the initiator. In both conditions, the leader's behavior at the initiation, the one of the followers when they joined the move and the joining latencies are systematically recorded and analyzed.

\section{Materials and methods}

\section{Animals}

Three groups of six female ponies (Equus ferus caballus) were observed for this study. Each group had been stabilized for at least six months before the beginning of the observation sessions and remained outdoors in pastures of at least one-hectare over the whole year (Group 1 and 2 in 2014 and Group 3 in 2015) at the Haut-Barr breeding farm in Saverne, France. Four individuals belonged to two different groups meaning that the analysis was based on fourteen individuals (mean age $7 \pm 2$ years). The hunger state of the individuals was presumably stable over time since they had ad libitum access to grass and hay.

\section{Collective movements} food reward (i.e., 18 large-sized carrots placed out of the sight of the group, 45 to $50 \mathrm{~m}$ away from the pen entrance). Half of the carrots formed a stack, and the other half was distributed randomly around the main stack (up to $3 \mathrm{~m}$ around) so that every individual could have access 
to food reward. In a second step, the informed animal was returned to the temporary pen. In a last step, the pen was opened and the informed horse could return to the food reward, thus initiating a collective movement. An initiation is defined as a movement of at least twenty steps away from the group without pausing and with the neck at or above the horizontal position (Bourjade et al., 2009; Briard et al., 2015). Similarly, a follower is defined as an individual which takes at least twenty steps away from the group in the same direction as the initiator. Every individual was tested at least four times in the role of the informed horse. If the informed horse did not initiate the movement, the test was considered to have failed. Three cameras were placed along the way (outside the pasture and hidden by vegetation): the first at the departure point, the second at the location where the carrots have been placed, and the third halfway between these two locations. To become unpredictable for the horses, the food reward and the temporary pen could be placed randomly at different locations in the pasture, and the same location was never used twice on the same day or on two consecutive days. At the group level, we did not observe any increase of initiation rate or joining across the study (First vs. last trial: initiator's arrival latency: Mean 1 st trial $\pm S E=112.2 \pm 38.3 \mathrm{~s}$, Mean last trial $\pm S E=72.67 \pm 26.8 \mathrm{~s}, \mathrm{~N}=15, \mathrm{~W}=43.5, \mathrm{NS}$, Wilcoxon test; last follower's arrival latency/total number of followers: Mean $_{1 \mathrm{st} \text { trial }} \pm \mathrm{SE}=36.7 \pm 11 \mathrm{~s}$, Mean $_{\text {last trial }} \pm \mathrm{SE}=14.5 \pm 3.7 \mathrm{~s}, \mathrm{~N}=15, \mathrm{~W}=30.5, \mathrm{NS}$, Wilcoxon test; number of followers: $M_{1 s} n_{1 s t}$ trial $\pm S E=4.5 \pm 0.3$, Mean last trial $\pm S E=4.9 \pm 0.1$, not enough variability for statistical analysis). Failed initiations occurred even during the last tests and the number of tests at the individual level was too small to encourage any habituation process.

\section{Spontaneous condition}

Each group was filmed during continuous and daily sessions of approximately six hours. The observation periods ran for nine consecutive days for a total recording period of 50 hours minimum per group. The criteria used to define an initiation of a collective movement and the joining processes in these experiments are identical to those described in the previous section.

\section{Data collected}

The data were all scored by the same person (CG) who was unaware of the working assumption at the scoring period. For every collective movement, video analysis was used to calculate the joining latencies between the initiation and the departure of each follower. Only movements involving at least one follower were considered. The success of a leader was 
estimated by calculating the total joining latency (i.e. the joining latency of the last follower divided by the number of followers).

The focal animal sampling method (Altmann, 1974) was used to record the behavior of leaders from departure to arrival for every initiation. The movement was discarded from the analysis when the initiator was not visible from the departure to the arrival or was no longer visible when the first follower departed. Four behaviors were considered to be perceptible signs for followers of the expressiveness of the leader. They were based on behaviors that are classically observed in literature about recruitment (Cebus capucinus: glances, pauses and speed (Meunier et al., 2008); Cygnus Cygnus: shaking head (Black, 1988)). The occurrence and proportion of the following behaviors were collected from the initiation until the first individual followed the initiator or until the initiator arrived at its destination: gait (presence of trot and/or gallop), raised head position (i.e., the time during which the initiator held its head raised), head shaking (number of events), pauses (duration) and glances (number of events). The two last behaviors occurred in only three initiations and were therefore excluded from the analysis. An expressiveness score was calculated according to the presence or absence of the three remaining behaviors. The score calculation was decided to avoid an overestimation of one behavior over another. The scale ran from zero (none of the three behaviors was emitted) to three (the three behaviors were emitted).

The behavior of other group members, including both followers and non-followers, was recorded using the scan sampling method (Altmann, 1974). A first scan was performed at the initiation step to assess whether group members could see the leader, as there are hedges in the pastures that can hide the initiator. A second scan was performed at the departure of every follower to record its joining rank as well as its head position, gait and head shaking. In this way, the expressiveness score was calculated for every follower.

If one of the followers was not visible when it departed, the movement was discarded from the analysis. In total, 42 experimental and 74 spontaneous movements were used for the analysis.

\section{Assessing dominance rank and centrality}

Agonistic interactions between individuals were continuously recorded during the observation sessions in the spontaneous condition. Unidirectional interactions corresponded to approaches, threats or aggressions which are responded to by clear avoidance alone. SOCPROG 2.5. was then applied to obtain a David's score (David, 1987) for each individual. 
The centrality index, or eigenvector, was based on proximity (Whitehead, 2009). During the observation sessions, inter-individual distances were collected every fifteen minutes with the scan sampling method (Altmann, 1974) and 200 scans were collected per group. Two individuals were considered close when the inter-individual distance was less than one meter. Indeed, this distance enables the individuals to interact without moving. The eigenvector was obtained using SOCPROG 2.5 and represents the total number of connections an individual has, including the connections between its partners. The higher this index is, the more central the individual is within the group.

\section{Assessing personality}

Personality tests were performed in spring 2014 on 12 individuals according to a simplified standardized protocol (for further details see Lansade et al., 2016). Finally, we obtained 11 indices of fearfulness and 10 indices of curiosity. The missing data for 4 individuals are explained by the fact that one horse was reluctant to move away from the group to be tested, interfered with the curiosity test of another one, and that these tests could not practically be repeated in 2015. The aim was to evaluate the reactivity of an individual to a novel or sudden stimulus in order to characterize one personality dimension: fearfulness. For every individual, three tests were successively performed in a precise order: unfamiliar object, unfamiliar surface and suddenness. An additional test was performed to evaluate curiosity.

During the first test, the handler led the horse around an unfamiliar object (Fig 1a) with a slack leading rein. Three zones were defined around the object: the first corresponded to a distance of up to two meters, the second was between two and four meters and the last was four meters or more. The number of the zones that the horse crossed at every quarter turn was recorded. The addition of these numbers for the entire turn provided a score that was higher if the horse was frightened. The number of glances towards the object was also recorded.

In the unfamiliar surface test, a bucket with appetent food was presented to the horse and then placed at the center of a $2 \mathrm{~m} \times 2 \mathrm{~m}$ black and orange plastic sheet (Fig $1 \mathrm{~b}$ ). Then the leading rein was left slack so the horse was free to move. The latency until the horse put one foot on the sheet to access the bucket was recorded as well as the time taken to eat the food.

The suddenness test consisted of rapidly opening and closing a large umbrella in front of the horse from a five-meter distance, then from a three-meter distance. The escape distance in each repetition was measured and a mean was calculated. 
Additionally, a curiosity test (not included in Lansade et al., 2016) was performed with the same object as the one used for the unfamiliar object test. The advantage of performing this test after the previous ones is that the object was no longer unknown. This made it possible to measure curiosity reactions while excluding the fearfulness dimension. The approach latency and the number of physical contacts with the object (sniffing, nibbling or nuzzling) over a 180 s period were recorded.

Finally, two Principal Component Analyses with R 3.1.3 (R Core Team, 2015) including all the results of the different tests provided a score for each individual for the fearfulness dimension (75.80\% on Dimension 1 ) and the curiosity dimension (72.56\% on Dimension 1 , see Online Resource 1 for figure).

\section{Statistical analysis}

All statistics were computed using the R 3.3.2 statistical environment (R Core Team 2016). Individual profiles of expressiveness

This analysis is the only analysis taking into account the identity of the leader. The individuals belonging to two different groups across years were considered as two different individuals in the analysis to assess an eventual change of expressiveness between the two years and social environment. A hierarchical cluster analysis with Ward's method was performed to classify initiations according to the initiator's expressiveness level. Time proportion spent raising head, time proportion spent galloping or trotting and shaking head occurrence variables were included (agnes function of Cluster package (Maechler, 2013). The catdes function of FactoMineR package (Lê et al., 2008), including a khi-2 test, was used to test the independence of qualitative variables (group and condition) and excluded the possibility of a group-effect (overrepresentation of a particular group in one category). The same function was then used to describe the obtained clusters and investigated which variables (both qualitative and quantitative) were characterizing the clusters.

\section{Expressiveness effect on followership}

The total joining latency was analyzed with a linear model using the expressiveness score, time proportion spent raising head, time proportion spent galloping or trotting, shaking head occurrence and condition as fixed effects (Ime function of $n / m e$ package (Pinheiro and Bates, 2017)). Individuals were nested in groups as a random effect, initiations then become anonymous and avoid group bias. Normality and homoscedasticity of residuals were visually 
joining latency was converted into logarithm to fit with a normal distribution. All variables were screened for excessive multicollinearity (VIF $>10$ due to the low number of variables) (vif function of car package (Fox and Weisberg, 2011)). This adjusted model included level 2 interactions with an LRT test approach (Imer function of Ime4 package (Bates et al., 2016)).

A first model solely included the initiations in which the initiator was visible to at least the first follower ( $\mathrm{N}=112 ; 38$ in the experimental condition and 74 in the spontaneous condition). A second model solely included the initiations from the previous selection in which the expressiveness score of the initiator was above zero (i.e. 1,2 or 3, N=40; 21 in the experimental condition and 19 in the spontaneous condition). The aim of this second model was to assess the expressiveness effect only when it was present.

\section{Social status effect on followership}

The same method was used to analyze total joining latency, using David's score and eigenvector as fixed effects and individuals nested in groups as random effects. To avoid experimental bias, only the spontaneous condition was considered. In a first step, we only included initiations in which the initiator was visible by at least the first follower $(N=74)$. A second model was then built that solely included the initiations from the previous selection in which the expressiveness score of the initiator was above zero (i.e. 1, 2 or 3, N=19). Finally, a third model was built for initiations in which the expressiveness score of the initiator was null $(\mathrm{N}=55)$. As previously, normality and homoscedasticity of residuals in every model were visually inspected (plot.Ime and qqplot.Ime functions of nlme package (Pinheiro and Bates, 2017)). The joining latency was converted into logarithm to fit with a normal distribution. All variables were screened for excessive multicollinearity (VIF $>10$ due to the low number of variables) (vif function of car package (Fox and Weisberg, 2011)). This adjusted model included level 2 interactions with an LRT test approach (Imer function of Ime4 package (Bates et al., 2016)).

\section{Contagion mood in followers}

The expressiveness score of every follower (Sn) was examined in successive generalized linear mixed models. The expressiveness scores of the previous individuals in the movement (from SO to Sn-1) were used as fixed effects and the individuals nested in a group and the condition as random effects. The score variable was transformed by dividing it by 3 (the maximum number of expressive behaviors), thus permitting the use of a binomial family error distribution in the model. All variables were screened for excessive multicollinearity (VIF >10 
because of the low number of variables) using the vif function of car package (Fox and Weisberg, 2011). This model was adjusted using an LRT test approach (g/mer function of Ime4 package (Bates et al., 2016)). We selected the initiations involving the whole group from all the initiations in which the initiator was visible by at least the first follower $(N=46 ; 36$ in experimental conditions and 10 in spontaneous conditions).

\section{Results}

\section{Individual profiles of expressiveness}

\section{1) Experimental condition}

The hierarchical cluster analysis extracted two categories: initiations with a low or a high level of expressiveness by the leader. The distribution is balanced, with 20 initiations in the first category (low expressiveness) and 22 in the second (high expressiveness). The leader is expressive in $52.40 \%$ of initiations. The means of the three behaviors significantly differ between low and high expressiveness category (time proportion spent raising head, low: $0.00 \pm 0.00 \%$ vs. high expressiveness category: $74.70 \pm 5.33 \%, \mathrm{P}<0.001$; time proportion spent galloping or trotting, low: $2.50 \pm 2.44 \%$ vs. high expressiveness category: $56.06 \pm 7.23 \%$, $P<0.001$; shaking head occurrence, low: $0.00 \pm 0.00$ per hour vs. high expressiveness: $0.36 \pm 0.10$ per hour, $\mathrm{P}<0.05)$. Furthermore, some individuals are seen in only one category whereas others can be found in either category, depending on the initiations. Finally, the mean of the curiosity score is significantly higher in the high expressiveness category (Fig 2$)(P<0.05)$, suggesting that the expressiveness is associated with a higher curiosity trait.

\section{2) Spontaneous condition}

The signs of expressiveness are less frequent in the spontaneous condition than in the experimental condition, occurring in only $17.60 \%$ of the initiations. However, the same categories, i.e., a low (61 initiations) or a high (13 initiations) level of expressiveness, were extracted for the spontaneous condition. Here again, the individuals are either found in one specific category or alternate between the two, but their distribution differs from the experimental condition.

Like in the experimental condition, the means of the three behaviors significantly differ between low and high expressiveness category (time proportion spent raising head, low: $3.28 \pm 2.28 \%$ vs. high expressiveness category: $61.15 \pm 25.60 \%, \mathrm{P}<0.0001$; time proportion spent galloping or trotting, low: $0.00 \pm 0.00 \%$ vs. high expressiveness category: $18.57 \pm 9.84 \%$, $\mathrm{P}<0.001$; shaking head occurrence, low: $0.00 \pm 0.00$ per hour vs. high expressiveness: $0.62 \pm 0.12$ 
per hour, $\mathrm{P}<0.001)$. Furthermore, the means of the curiosity scores are not significantly different between the two categories. Nevertheless, the eigenvector (Fig 3) and David's score means (Fig 4) are significantly higher in the low expressiveness category (eigenvector: $\mathrm{P}<0.05$; David's Score: $\mathrm{P}<0.001)$ suggesting that the expressiveness is associated with low centrality and subordinate status.

\section{Effect of expressiveness on followership}

After the analysis of all the initiation data collected, the best predictor model includes the condition variable, indicating that joining latency is significantly longer in the spontaneous condition than in the experimental one (Table 1) (Student test, $\mathrm{Df}=1, \mathrm{t}=3.43, \mathrm{P}<0.001$ ). The best predictor model for initiations in which the expressiveness score of the leader is not null is the one that only included the score variable, which is negatively and significantly related to joining latency (Table 1) (Student test, $\mathrm{Df}=1, \mathrm{t}=-2.23, \mathrm{P}<0.05$ ). It suggests that the more expressive the leader is, the faster the followers will join the movement.

\section{Social status effect on followership}

With all the initiations included, the best predictor model for joining latency is the null model, suggesting that neither dominance nor centrality status has a clear effect. We obtain the same result for the initiations in which there is no sign of expressiveness (i.e. score null) and those in which we can observe an expressive leader (i.e. score equal to 1, 2 or 3 ). Thus, whatever the level of expressiveness expressed by the leader, its dominance and centrality status are not clearly related to its success.

\section{Contagion mood in followers}

In each of the successive models, the best predictor model only includes the score of the individual immediately preceding each follower in the movement (Table 2). Thus, the expressiveness of the first follower (S1) is positively and significantly related to the expressiveness of the leader (SO) (Wald test, $\mathrm{z}=2.01, \mathrm{P}<0.05$ ). Similarly, the expressiveness of the second follower (S2) is positively and significantly related to the expressiveness of the first follower (S1) (Wald test, $\mathrm{z}=3.34, \mathrm{P}<0.001$ ). The score of the third follower (S3) is also positively and significantly related to the score of the second joiner (S2) (Wald test, $z=4.80, P<0.001$ ). Finally, the expressiveness of the fourth follower (S4) is positively and significantly related to the expressiveness of the third follower (S3) (Wald test, $\mathrm{z}=3.50, \mathrm{P}<0.001$ ). This rule does not apply for the last follower, as its expressiveness score (S5) is positively and significantly related to that of the third follower (S3) (Wald test, $\mathrm{z}=2.92, \mathrm{P}<0.05)$. 


\section{Discussion}

\section{Individual profiles of expressiveness}

These results show a high degree of variability in the expressiveness of leaders across initiations. This is illustrated by the presence of two different categories. The first (low expressiveness category) includes the initiations during which few or no signs of expressiveness were observed in the leader's behavior, and the second (high expressiveness category) concerns the initiations in which the leader is highly expressive. Between these two categories, the means of the three behaviors are significantly different, indicating that these variables are efficiently discriminant, without any one of them being more representative than another. These clusters enable us to validate the relevance of the behaviors we selected and the expressiveness score we built.

This study fails to distinguish stable individual profiles of expressiveness. Nevertheless, the results show a higher propensity to initiate being more expressive in the experimental condition (54.2\% of the initiations in the high expressiveness category) than in the spontaneous condition (only $17.6 \%$ ). This result is not surprising since the experimental procedure aims to increase the motivation of initiators with a highly appetent reward in order to provoke direct and standardized initiations. However, it must be specified that, even in the spontaneous condition, we obtained large variations in the score of expressiveness between the different initiations. Furthermore, in the experimental condition, the curiosity score of the expressive leaders (high expressiveness category) is higher than that found in leaders displaying no sign of expressiveness. It indicates that curious individuals seem to be more prone to initiate with a higher level of expressiveness. This relationship is not observed in the spontaneous condition, highlighting the importance of context in the relationships between personality and leadership. Changes from the context that animals routinely encounter could enhance the motivation of curious individuals to initiate, and thus explain why this result is only obtained in the experimental condition. Although personality has never been shown to be a necessary factor for individual success, this link between personality and leadership has previously been revealed in horses, where bold individuals were seen to initiate more often than others (Briard et al., 2015). The same results were obtained in Olive baboons (Papio hamadryas ursinus), where males initiated raids on crops more often than females. All of these could be explained by a propensity to be active in unusual and novel contexts (Schweitzer et al., 2017). 
In the spontaneous condition, the dominance and centrality indexes of the leader are lower in the high expressiveness category. This indicates that the subordinate and/or peripheral individuals seem to be more prone to be highly expressive when initiating movements. It may suggest that these individuals compensate their status by their level of expressiveness. Indeed, a high hierarchical position has been shown to facilitate leader success (in gorillas (Gorilla gorilla) (Watts, 2000), wolves (Canis lupus) (Mech, 1970), and mongooses (Helogale undulata rufula ) (Anne and Rasa, 1983)). Nevertheless, our results are based on a restricted number of individuals. The findings would benefit being supported by future additional studies. Finally, if the level of leader's expressiveness has a real effect on the followers, individuals with a low social status could compensate for their relatively weak position and influence group members by being more expressive than the dominant and central initiators and consequently obtain similar levels of success. It has been shown that horses might have a representation of their social position in their group (Krueger and Heinze, 2008), but this phenomenon of compensation also raises the question of a horse's ability to be aware of how its own behavior influences others. However, caution should be taken when considering the intentionality of such a behavior, as operant conditioning would suffice to explain the emergence of expressiveness. Indeed, the expressive behavior could have been associated with a positive reaction from another individual (i.e. success), thus leading to positive reinforcement (Bouton, 2016). This could therefore be a case of social conditioning, insofar that individuals adjust their behavior according to the reactions of their congeners from a very early age (Ducoing and Thierry, 2003).

\section{The effect of expressiveness on followership}

When all initiations are analyzed, the only significant effect on the joining latency is the condition. The joining process is faster in the experimental condition than in the spontaneous condition. Here again, the result can be explained by the motivation increase caused by the reward. If we consider the higher frequency of expressive initiations in this condition, we can conclude that this increase in motivation affects both the leaders and the followers through increased expressive behaviors and joining speed, respectively. Indeed, as a grazing species, healthy horses are known to be constantly motivated by highly palatable food (McGreevy and Mc Lean, 2010), and carrots are very appetizing. As a consequence, motivation for food might be an important driver for all the group members to move more in the experimental condition than in the spontaneous condition. However, this increase in motivation can also be explained 
by all the parameters that are generally favorable for both initiating and following in the experimental condition, such as the spatial proximity, the good visibility on each other's behavior, or the fact that trajectories are direct. Nevertheless, no causality link can be established between leader expressiveness and joining speed at this stage.

When only the initiations in which the leader showed at least one of the expressiveness behaviors are included, the expressiveness score appears to be negatively and significantly related to the joining latency. It therefore seems that the level of expressiveness shown by the leader increases its success in terms of joining speed, but only if the expressiveness score is above zero. Indeed, if the leader does not express any sign, the joining latency varies from one extreme to another and is probably dependent on other parameters. However, if the leader expresses these signs, they seem to become a decisive factor for the decision-making process of group members.

\section{Effect of social status on followership}

Similar to the conclusion drawn about previous results in horses (Bourjade et al., 2015; Briard et al., 2015), we do not find any significant relation between the dominance status or centrality of a leader and its success in terms of joining speed. We expected this study to explain the absence of a consistent link between dominance status and leadership in previous studies in horses (Bourjade et al., 2015; Briard et al., 2015) by an additional factor that hid this effect, but no evidence was found that expressiveness was responsible for this absence of a link in the population studied.

\section{Contagion mood in followers}

This study shows that the score of expressiveness of the preceding individual in the movement is positively and significantly related to the next follower. This result suggests a chain reaction that spreads expressiveness from the leader through to the fourth follower and then to the final one. The result for the fifth follower is necessarily biased owing to its position in the movement. Its individual decision process is probably strongly influenced by the risk of social isolation if it does not follow.

This contagion mood could be one of the modalities explaining the effect of leader expressiveness on joining speed. Every follower may transmit a kind of impulse to the next individual, enhancing its motivation. This type of phenomenon has already been observed in animals, and particularly in a positive context following the reunion of individuals that had 
been experimentally separated. These events, named collective arousal, demonstrated a contagion mood based on non-verbal communication, imitation and synchronization processes between individuals (De Marco et al., 2011).

Finally, like in mimetic processes (Camazine et al., 2001), only the first follower needs to be influenced by the leader expressiveness for this influence to be transmitted through every follower's behavior. This mechanism could therefore efficiently maintain the impulse of the leader and finally enhance the social cohesion of the group (De Marco et al., 2011) and its coordination (Bono and Ilies, 2006). We think that the contagion mood via a mimetic process is a very interesting process that merits further investigation, as this mechanism may allow group cohesion for groups of all sizes.

\section{Conclusion and perspectives}

The present study demonstrates that horses can be more or less expressive when initiating a collective movement, and that this expressiveness can help the leader to be followed. This positive and dynamic attitude can be perceived as an attractive feature by the followers and could be close to the leader's charisma as found in humans. Interestingly, the expressiveness observed in our study was mainly shown by subordinate individuals and more often by socially peripheral group members, suggesting that they may increase their level of expressiveness in order to be followed. This potential compensation of social status through behavior by subordinate and peripheral individuals may support the theory of a form of emotional intelligence in horses i.e., the capacity to recognize and influence the emotions of congeners. Indeed, in humans, regardless of variations in his/her own emotional state, the leader can use his/her intelligence to maintain a positive attitude whatever the situations (Bono and Judge, 2004). Such emotional intelligence could enable individuals to have voluntary control over their behavior and moderate their expression depending on the individuals around them (Walter and Bruch, 2009). Finally, this attractiveness of the leader through its positive and dynamic attitude, as well as this possible kind of social compensation, shapes a leadership pattern that recalls the charismatic leadership model developed in the human literature (Walter and Bruch, 2009).

To conclude, our study provides the first analysis of expressiveness in animals and yields some encouraging avenues for future research. Furthermore, we believe that the concept of charisma could be applied to a non-human species and is a very promising opportunity for future research about leadership origins. 


\section{Ethical Note}

All the experiments undertaken in this study complied with ethical standards of French research practices. The authorization number is $\mathrm{AL} / 01 / 10 / 07 / 11$ for the Regional Ethical Comity for Animal Experimentation (CREMEAS). Neither procedure adversely affected the horses in the short term or for the overall period of the study.

\section{References}

Altmann, J., 1974. Observational study of behavior: sampling methods. Behaviour 49, 227266.

Anne, O., Rasa, E., 1983. Dwarf mongoose and hornbill mutualism in the Taru desert, Kenya. Behav. Ecol. Sociobiol. 12, 181-190.

Bates, D., Maechler, M., Bolker, B., Walker, S., Christensen, R.H.B., Singmann, H., Dai, B., Grothendieck, G., Green, P., Bolker, M.B., 2016. Package "Ime4," in: R Package Version 1.1-10.

Berger, J., 1977. Organizational systems and dominance in feral horses in the Grand Canyon. Behav. Ecol. Sociobiol. 2, 131-146.

Black, J.M., 1988. Preflight signalling in swans: a mechanism for group cohesion and flock formation. Ethology 79, 143-157.

Bono, J.E., llies, R., 2006. Charisma, positive emotions and mood contagion. Leadersh. Q. 17, 317-334.

Bono, J.E., Judge, T.A., 2004. Personality and Transformational and Transactional Leadership: A Meta-Analysis. J. Appl. Psychol. 89, 901-910.

Bourjade, M., Thierry, B., Hausberger, M., Petit, O., 2015. Is Leadership a Reliable Concept in Animals? An Empirical Study in the Horse. PLoS ONE 10, e0126344.

Bourjade, M., Thierry, B., Maumy, M., Petit, O., 2009. Decision-Making in Przewalski Horses ( Equus ferus przewalskii ) is Driven by the Ecological Contexts of Collective Movements. Ethology 115, 321-330.

Bouton, M.E., 2016. Learning and behavior: a contemporary synthesis, Second edition. ed. Sinauer Associates, Inc., Publishers, Sunderland, Massachusetts.

Briard, L., Deneubourg, J.-L., Petit, O., 2017. How stallions influence the dynamic of collective movements in two groups of domestic horses, from departure to arrival. Behav. Processes.

Briard, L., Dorn, C., Petit, O., 2015. Personality and Affinities Play a Key Role in the Organisation of Collective Movements in a Group of Domestic Horses. Ethology 121, 888-902.

Camazine, S., Bonabeau, E., Théraulaz, G., Deneubourg, J.-L., Sneyd, J., Franks, N.R., 2001. Self-organization in biological systems. Princeton Univ. Press, p. 538, Princeton, NJ.

Conradt, L., Roper, T.J., 2005. Consensus decision making in animals. Trends Ecol. Evol. 20, 449-456.

Conradt, L., Roper, T.J., 2003. Group decision-making in animals. Nature 421, 155-158.

Corbin, M., Bouvet, G., Briard, L., Petit, O. Collective behavior in horses: do physiological needs determine movement initiation? Ecology \& Behavior, Toulouse, 19-24 May 2019.

David, H.A., 1987. Ranking from unbalanced paired-comparison data. Biometrika 74, 432436. 
De Marco, A., Cozzolino, R., Dessì-Fulgheri, F., Thierry, B., 2011. Collective arousal when reuniting after temporary separation in Tonkean macaques. Am. J. Phys. Anthropol. 146, 457-464.

Ducoing, A.M., Thierry, B., 2003. Withholding information in semifree-ranging Tonkean macaques (Macaca tonkeana). J. Comp. Psychol. 117, 67-75.

Feist, J.D., McCullough, D.R., 1976. Behavior patterns and communication in feral horses. Z. Für Tierpsychol. 41, 337-371.

Fischhoff, I.R., Sundaresan, S.R., Cordingley, J., Larkin, H.M., Sellier, M.-J., Rubenstein, D.I., 2007. Social relationships and reproductive state influence leadership roles in movements of plains zebra, Equus burchellii. Anim. Behav. 73, 825-831.

Fox, J., Weisberg, S., 2011. An R Companion to Applied Regression, Second. ed. Sage.

Jacobs, A., Sueur, C., Deneubourg, J.L., Petit, O., 2011. Social Network Influences Decision Making During Collective Movements in Brown Lemurs (Eulemur fulvus fulvus). Int. J. Primatol. 32, 721-736.

Johnstone, R.A., 1996. Multiple Displays in Animal Communication:'Backup Signals' and 'Multiple Messages'. Philos. Trans. R. Soc. B Biol. Sci. 351, 329-338.

Krueger, K., Flauger, B., Farmer, K., Hemelrijk, C., 2014. Movement initiation in groups of feral horses. Behav. Processes 103, 91-101.

Krueger, K., Heinze, J., 2008. Horse sense: social status of horses (Equus caballus) affects their likelihood of copying other horses' behavior. Anim. Cogn. 11, 431-439.

Lansade, L., Philippon, P., Hervé, L., Vidament, M., 2016. Development of personality tests to use in the field, stable over time and across situations, and linked to horses' show jumping performance. Appl. Anim. Behav. Sci. 176, 43-51.

Lê, S., Josse, J., Husson, F., others, 2008. FactoMineR: an R package for multivariate analysis. J. Stat. Softw. 25, 1-18.

Maechler, M., 2013. Cluster analysis extended Rousseeuw et al. R CRAN.

McComb, K., Moss, C., Durant, S.M., Baker, L., Sayialel, S., 2001. Matriarchs As Repositories of Social Knowledge in African Elephants. Science 292, 491-494.

McGreevy, P., McLean, A. 2010. Equitation Science. John Wiley \& Sons ed., Oxford, UK, 328 p.

Mech, L.D., 1970. The wolf: the ecology and behavior of an endangered species. Univeristy of Minnesota Press (2003),p. 416, Minneapolis, Minn.

Meunier, H., Deneubourg, J.-L., Petit, O., 2008. How many for dinner? Recruitment and monitoring by glances in capuchins. Primates 49, 26-31.

Petit, O., Bon, R., 2010. Decision-making processes: The case of collective movements. Behav. Processes 84, 635-647.

Pinheiro, J., Bates, D., 2017. Linear and Nonlinear Mixed Effects Models.

Ramos, A., Petit, O., Longour, P., Pasquaretta, C., Sueur, C., 2015. Collective decision making during group movements in European bison, Bison bonasus. Anim. Behav. 109, 149160.

Ramseyer, A., Petit, O., Thierry, B., 2009a. Decision-making in group departures of female domestic geese. Behaviour 146, 351-371.

Ramseyer, A., Thierry, B., Boissy, A., Dumont, B., 2009b. Decision-making Processes in Group Departures of Cattle. Ethology 115, 948-957.

Schweitzer, C., Gaillard, T., Guerbois, C., Fritz, H., Petit, O., 2017. Participant Profiling and Pattern of Crop-Foraging in Chacma Baboons (Papio hamadryas ursinus) in Zimbabwe: Why Does Investigating Age-Sex Classes Matter? Int. J. Primatol. 38, 207223. 
Sueur, C., 2011. Group decision-making in chacma baboons: leadership, order and communication during movement. BMC Ecol. 11, 26.

Sueur, C., Petit, O., 2008a. Organization of Group Members at Departure Is Driven by Social Structure in Macaca. Int. J. Primatol. 29, 1085-1098.

Sueur, C., Petit, O., 2008b. Shared or unshared consensus decision in macaques? Behav. Processes 78, 84-92.

Sueur, C., Petit, O., Deneubourg, J.L., 2009. Selective mimetism at departure in collective movements of Macaca tonkeana: an experimental and theoretical approach. Anim. Behav. 78, 1087-1095.

Walter, F., Bruch, H., 2009. An Affective Events Model of Charismatic Leadership Behavior: A Review, Theoretical Integration, and Research Agenda. J. Manag. 35, 1428-1452.

Watts, D.P., 2000. Mountain gorilla habitat use strategies and group moup movements, in: On the Move: How and Why Animals Travel in Groups. Boinski,S., Garber,P.A., Chicago, pp. 352-374.

Whitehead, H., 2009. SOCPROG programs: analysing animal social structures. Behav. Ecol. Sociobiol. 63, 765-778.

\section{Captions}

Fig 1: Objects used during the fear tests

a. Unfamiliar object: blue plastic sheet ( $h=1.3 \mathrm{~m} \times \mathrm{L}=1.5 \mathrm{~m}$ ) to which colorful plastic toys have been attached by short strings, fixed on a wooden structure.

b. Unfamiliar surface: black and orange plastic sheet $(2 \mathrm{~m} \times 2 \mathrm{~m})$.

\section{Fig 2: Curiosity score mean in the experimental condition}

The means are significantly different between the Low and High expressiveness categories $\left({ }^{*} \mathrm{P}<0.05\right)$. Error bars represent standard error of the mean.

\section{Fig 3: Eigenvector mean in the spontaneous condition}

The means are significantly different between the Low and High expressiveness categories $\left({ }^{*} \mathrm{P}<0.05\right)$. Error bars represent standard error of the mean.

Fig 4: David's score mean in the spontaneous condition

The means are significantly different between the Low and High expressiveness categories $\left({ }^{* *} \mathrm{P}<0.001\right)$. Error bars represent standard error of the mean.

\section{Table 1: The best predictor models for the joining latency}

The first line represents the best predictor model when all the initiations were included. The second line represents the best predictor model for the initiations in which the expressiveness score of the leader is equal to zero.

Table 2: The best predictor models for the expressiveness score of the followers 
640 The only variable that is significantly related to the expressiveness score of an individual is the score 641 of the direct previous individual in the movement. The last joiner is not included in this rule.

642 


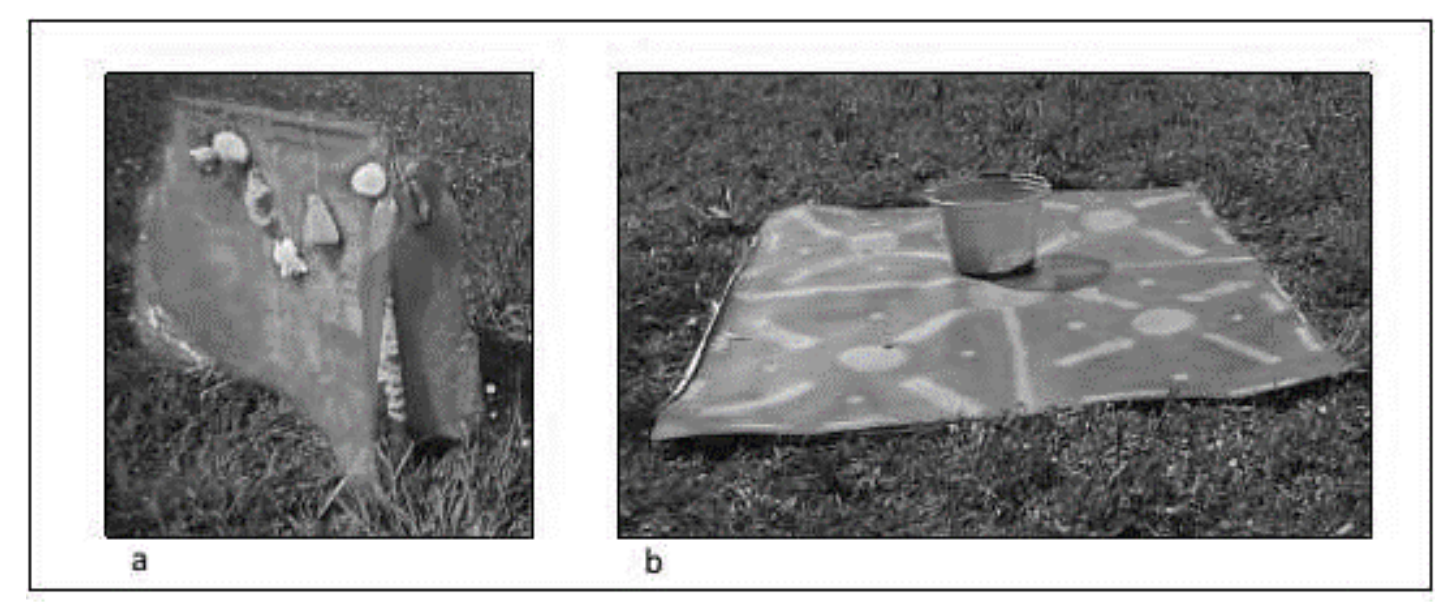

Figure1 


\section{Figure2}

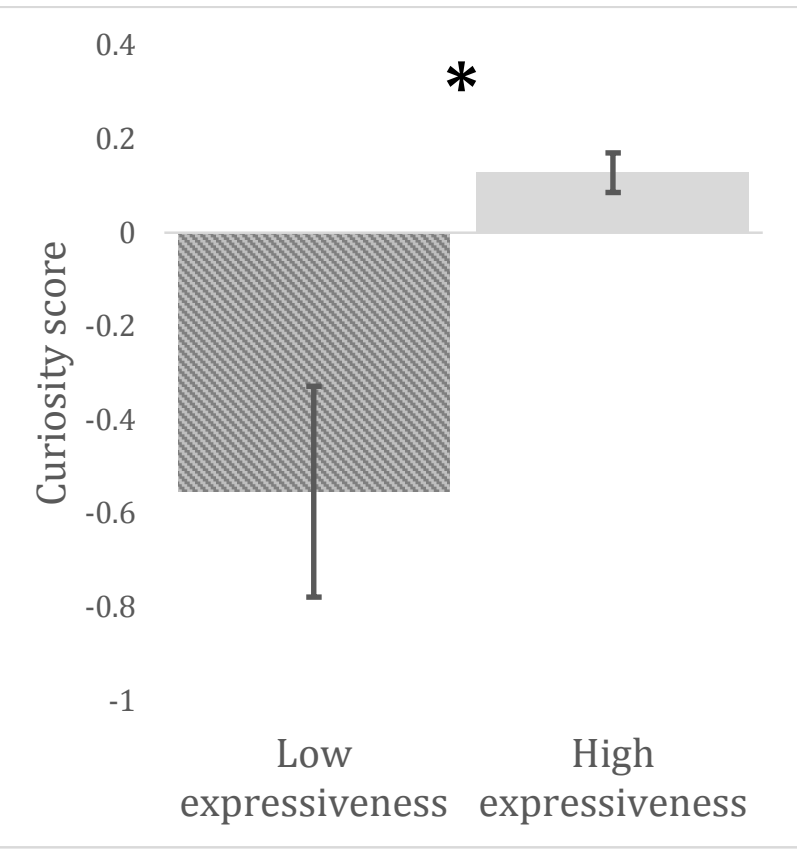


Figure3

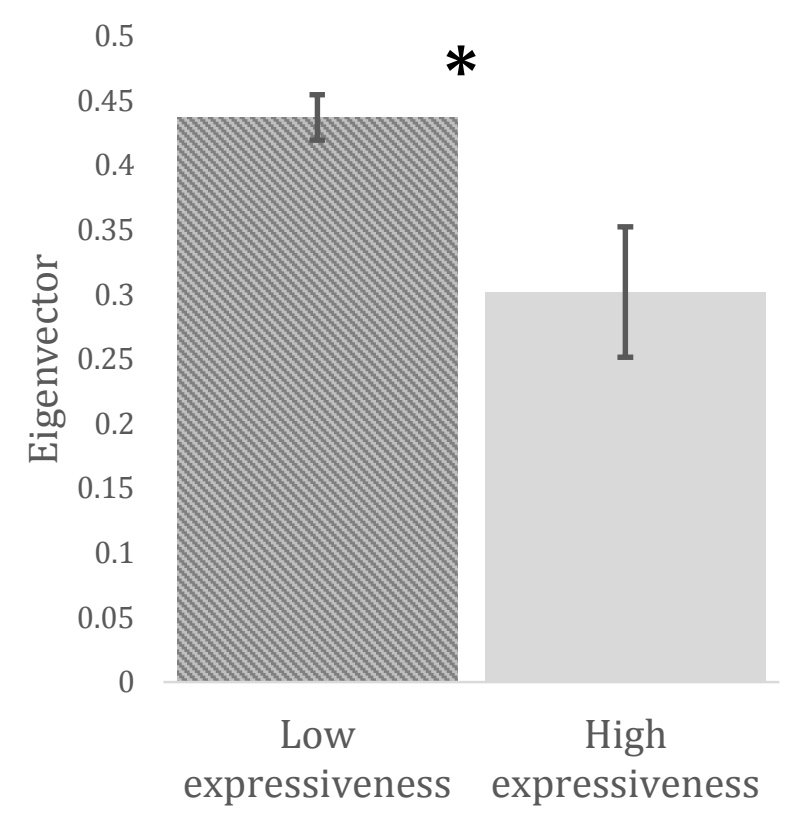


Figure4

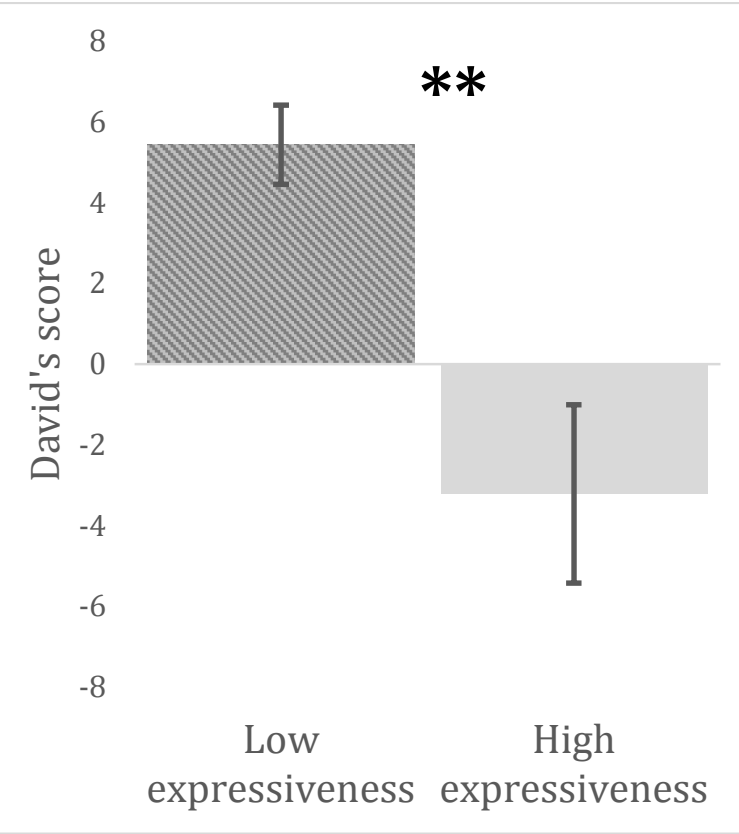


Table 1: The best predictor models for the joining latency

The first line represents the best predictor model when all the initiations were included. The second line represents the best predictor model for the initiations in which the expressiveness score of the leader is equal to zero.

\begin{tabular}{llllll}
\hline $\begin{array}{l}\text { Initiations } \\
\text { inclusion }\end{array}$ & $\begin{array}{l}\text { Variable to } \\
\text { explain }\end{array}$ & $\begin{array}{l}\text { Variable with } \\
\text { fixed effect }\end{array}$ & Estimate & Standard Error & P-value \\
\hline All scores & Joining latency & Spontaneous condition & 0.997 & 0.290 & 0.0009 \\
Scores $>0$ & Joining latency & Expressiveness score & -0.718 & 0.322 & 0.035 \\
\hline
\end{tabular}


Table 2: The best predictor models for the expressiveness score of the followers.

The only variable that is significantly related to the expressiveness score of an individual is the score of the direct previous individual in the movement. The last joiner is not included in this rule.

\begin{tabular}{lllll}
\hline $\begin{array}{l}\text { Variable to } \\
\text { explain }\end{array}$ & $\begin{array}{l}\text { Variable with } \\
\text { fixed effect }\end{array}$ & Estimate & Standard Error & P-value \\
\hline S1 & S0 & 0.381 & 0.589 & 0.0084 \\
S2 & S1 & 0.676 & 0.202 & 0.0008 \\
S3 & S2 & 0.850 & 0.177 & 0.0000016 \\
S4 & S3 & 0.749 & 0.214 & 0.00046 \\
S5 & S3 & 0.680 & 0.232 & 0.0035 \\
\hline
\end{tabular}

